\title{
Grupo de Orientação a Indivíduos Acometidos por Doenças Reumáticas: Espaço Educativo e Terapêutico
}

\section{Tutorial Group for People with Rheumatic Diseases: Educational and Therapeutic Space}

\author{
Maria Gabriela Reis Carvalho(1), Johanna Noordhoek ${ }^{(2)}$, Maria Cristina de Oliveira Silva ${ }^{(3)}$
}

\section{INTRODUÇÃO}

Uma das doenças crônicas mais comumente relatadas é artrite reumatóide (AR), acometendo cerca de $1 \%$ da população mundial ${ }^{(1)}$. A AR é uma doença sistêmica, de curso progressivo, cuja principal manifestação é a inflamação $\operatorname{articular}^{(2)}$. A dor crônica, a fadiga e a incerteza sobre o curso da doença relacionam-se muito frequentemente às dificuldades funcionais afetivas, comportamentais e sociais e, conseqüentemente, a graus variados de dificuldades na execução das atividades de vida diária, trabalho e $\operatorname{lazer}^{(3)}$. Devido ao curso progressivo da doença e às limitações correlatas, terapeutas ocupacionais assumem um importante papel no processo de tratamento de pessoas com AR. Com os objetivos de promover a habilidade de desempenho em atividades diárias, prevenir perdas funcionais e propor adaptações adequadas, de modo que o indivíduo possa continuar com sua vida produtiva, a terapia ocupacional emprega, como uma das modalidades de tratamento, a educação do paciente por meio de um modelo grupal de intervenção. Um programa educacional tradicional para indivíduos acometidos por doenças reumáticas inclui princípios de conservação de energia, técnicas de simplificação do trabalho, programa de exercícios e técnicas de proteção $\operatorname{articular}^{(3)}$.

Considerando-se a alta incidência de doenças reumáticas no Brasil, as limitações funcionais, e a importância da educação do indivíduo e do trabalho em grupo para a manutenção de sua qualidade de vida, o Departamento de Terapia Ocupacional da Universidade Federal de Minas Gerais (UFMG) criou, em 1996, o Projeto de Extensão "Orientação a Indivíduos Acometidos por Doenças Reumáticas", voltado à educação e suporte de indivíduos da comunidade. Com base em dados de um levantamento descritivo, o grupo de participantes do projeto é composto, majoritariamente, por indivíduos com idade superior a 60 anos $(53,33 \%)$ e do sexo feminino $(93,33 \%)$. O estudo verificou ainda que a maioria dos indivíduos é profissionalmente inativa $(73,33 \%)$ e recebe até um salário mínimo (60\%). Em relação à AR, 46,6\% dos participantes têm um tempo de evolução da doença entre 10 e 20 anos, sendo a queixa principal, em $53,33 \%$ dos casos, a dor ${ }^{(4)}$. O projeto tem como objetivos principais possibilitar, por meio de atendimentos em grupo, a educação, socialização dos pacientes, desenvolvimento de habilidades pessoais, novas possibilidades de enfrentamento da doença e melhor desempenho de papéis ocupacionais, melhorando os aspectos psicofísicos relacionados à doença e contribuindo para o incremento da qualidade de vida dos participantes.

\section{METODOLOGIA}

Os atendimentos são realizados em grupo, uma vez por semana, às sextas-feiras pela manhã, com duração de uma hora e trinta minutos. A coordenação é feita por um docente do Departamento de Terapia Ocupacional da UFMG e a monitoração é realizada por discentes voluntários e bolsistas do projeto de extensão. No grupo são realizados exercícios

1. Estudante de Terapia Ocupacional da Escola de Educação Física, Fisioterapia e Terapia Ocupacional da Universidade Federal de Minas Gerais (UFMG).

2. Professora Assistente do Departamento de Terapia Ocupacional da Escola de Educação Física, Fisioterapia e Terapia Ocupacional da UFMG.

3. Professora Assistente do Departamento de Terapia Ocupacional da Escola de Educação Física, Fisioterapia e Terapia Ocupacional da UFMG. 
terapêuticos de relaxamento e alongamento; atividades de socialização e lazer; palestras interativas e com médicos, nutricionistas, musicoterapeutas, psicólogos, fisioterapeutas e terapeutas ocupacionais. Busca-se, assim, o conhecimento sobre AR, convívio com a doença, tratamento medicamentoso, dieta, exercícios, posicionamento de repouso, controle da dor, conservação de energia e relaxamento, aumento do senso de competência e de autocuidado, e o empoderamento do indivíduo de seu processo de saúde. As atividades realizadas no grupo têm caráter dinâmico, ou seja, são baseadas na demanda dos participantes, de acordo com suas necessidades e interesses.

A cada semestre, o projeto de extensão universitária, numa ação de maior integração com o ensino, torna-se um espaço para as aulas práticas da disciplina de Recursos Terapêuticos I, ofertada ao quarto período da graduação em terapia ocupacional da UFMG. Quatro dos 20 atendimentos semestrais são facilitados pelos estudantes, sob a orientação do docente responsável. Assim, os alunos, propondo e vivenciando a aplicação dos recursos terapêuticos estudados, encontram no grupo de orientação a oportunidade de uma primeira experiência clínica com pacientes acometidos por disfunções físicas. Em contrapartida, os atendimentos aos pacientes foram enriquecidos com propostas de atividades lúdicas e expressivas.

Periodicamente, são realizadas avaliações qualitativas que visam identificar o grau de satisfação do paciente em relação ao grupo e às atividades desenvolvidas. Além disso, questionários de avaliação sobre a integração ensino-extensão foram desenvolvidos e aplicados a pacientes e alunos da graduação que participam do projeto.

\section{RESULTADOS E DISCUSSÃO}

Desde sua criação, o grupo de "Orientação a Indivíduos Acometidos por Doenças Reumáticas" já atendeu cerca de 250 indivíduos da comunidade, os quais exerceram papel ativo na construção das ações em seu benefício. Avaliações qualitativas realizadas com os participantes demonstraram crescente interesse pelos atendimentos, redução da dor, maior senso de competência, maior capacidade de enfrentamento da doença, aumento da socialização e incremento na percepção da qualidade de vida, o que vai ao encontro dos principais objetivos do projeto e dos resultados de vários outros estudos que verificaram a eficácia de programas educacionais no bem-estar físico e psíquico dos indivíduos acometidos por doenças reumáticas ${ }^{(5,6)}$.

O projeto possibilitou ainda maior integração entre extensão e ensino ao envolver em seu curso quatro alunos bolsistas e 30 alunos voluntários. Além disso, o projeto é espaço de aulas práticas da disciplina de Recursos Terapêuticos I, ofertada ao quarto período da graduação em terapia ocupacional da UFMG. Desse modo, além dos bolsistas e voluntários, 330 alunos passaram pelo projeto nos cinco últimos anos.

A produção científica relacionada ao projeto encontra-se em expansão. Já foram produzidos dois artigos, sendo que um deles foi publicado em revista periódica científica e o outro aguarda publicação, quatro trabalhos foram apresentados em eventos científicos e um projeto de pesquisa está sendo desenvolvido. Além de trabalhos de cunho científico, o projeto em questão produziu ainda uma cartilha ilustrada de orientação sobre proteção articular em doenças reumáticas, a qual é distribuída gratuitamente aos participantes do grupo.

\section{CONCLUSÃO}

A prevalência de doenças crônicas na população mundial tem aumentado nos últimos anos, sendo a AR uma das doenças crônicas mais comumente relatadas. De curso progressivo, a AR conduz a implicações funcionais significativas. A educação através do grupo é uma importante modalidade do tratamento empregada pela terapia ocupacional ao paciente acometido pelas doenças reumáticas. Criado em 1996, pelo Departamento de Terapia Ocupacional da UFMG, o projeto "Orientação a Indivíduos Acometidos por Doenças Reumáticas”, numa abordagem psicossocial e educacional, têm se mostrado um espaço de interação, integração e tratamento eficiente na melhora dos aspectos psicofísicos e, principalmente, da qualidade de vida dos indivíduos acometidos por doenças reumáticas. Além de dialogar com a sociedade, o projeto vem permitindo ainda uma importante articulação entre o ensino, a pesquisa e a extensão universitária ao contar com a participação de alunos bolsistas e voluntários, ser campo de aulas práticas de uma disciplina da graduação em terapia ocupacional, e ao servir como base para uma considerável produção científica. Como proposta de um projeto de extensão universitária, porém, o grupo de "Orientação a Indivíduos Acometidos por Doenças Reumáticas" ainda necessita de uma maior aproximação com os outros setores da sociedade e movimentos sociais, de modo a contribuir com o desenvolvimento regional e com a superação de desigualdades. 
REFERÊNCIAS

1. Houli J: Estudo Clínico da Artrite Reumatóide. In: Reumatologia clínica. Rio de Janeiro, Guanabara Koogan, 7: 171-212, 1973.

2. Salter RB: Distúrbios de ossos e articulações. In: Distúrbios e lesões do sistema musculoesquelético. São Paulo, MEDSI, $3^{\text {a }}$ ed, 10: 209-258, 2001.

3. Feirenberg JR, Trombly CA: In: Occupational therapy for physical dysfunction. Baltimore, Willians \& Wilkins, 4th, 1995.

4. Noordhoek J, Goulart F, Loschiavo FQ: Estudo descritivo dos pacientes atendidos no projeto de extensão de orientação aos indivíduos acometidos por doenças reumáticas. In: Congresso Brasileiro de Extensão Universitária, Belo Horizonte, 2004.

5. Barlow $\mathrm{JH}$ et al: Instilling the strenght to fight the pain and get on with life: learning to become an arthritis self-manager throught an adult education program. Health Education Research 4: 533-544, 1999.

6. Helliwell PS et al: A 12-month randomized controlled trial of patient education on radiographic changes and quality of life in early rheumatoid arthritis. Rheumatology 38: 303-308, 1999. 